\title{
Quality of life in isolated dystonia - non-motor manifestations matter
}

Johanna Junker, $\mathrm{MD}^{1,2}$, Brian D. Berman, MD, MS ${ }^{3,4}$, James Hall, Dphil' ${ }^{5}$, Deena Wahba, $\mathrm{MS}^{6}$, Valerie Brandt, $\mathrm{PhD}^{7}$, Joel S. Perlmutter, $\mathrm{MD}^{8}$, Joseph Jankovic, $\mathrm{MD}^{9}$, Irene A. Malaty, $\mathrm{MD}^{10}$, Aparna Wagle Shukla, $\mathrm{MD}^{10}$, Stephen G. Reich, MD ${ }^{11}$, Alberto J. Espay, MD ${ }^{12}$, Kevin R. Duque, MD ${ }^{12}$, Neepa Patel, MD $^{13}$, Emmanuel Roze, $\mathrm{MD}, \mathrm{PhD}^{14,15}$, Marie Vidailhet, $\mathrm{MD}^{14,15}$, H. A. Jinnah, MD, PhD ${ }^{16}$, Norbert Brüggemann, $\mathrm{MD}^{1,2}$

\footnotetext{
${ }^{1}$ Institute of Neurogenetics, University of Luebeck, Luebeck, Germany

2 Department of Neurology, University of Luebeck, Luebeck, Germany

${ }^{3}$ Department of Neurology, University of Colorado Anschutz Medical Campus, Aurora, CO, USA

${ }^{4}$ Neurology Section, Denver VA Medical Center, Denver, CO, USA

${ }^{5}$ Southampton Education School, University of Southampton, UK

${ }^{6}$ BayCare Laboratories, Tampa, FL, USA

${ }^{7}$ School of Psychology, Centre for Innovation in Mental Health, University of Southampton, UK

${ }^{8}$ Departments of Neurology, Radiology, Neuroscience, Physical Therapy \& Occupational Therapy, Washington University in St. Louis, St. Louis, MO, USA

9 Parkinsons' Disease Center and Movement Disorders Clinic, Department of Neurology, Baylor College of Medicine, Houston, Texas, USA

${ }^{10}$ Department of Neurology, Fixel Institute for Neurologic Disorders, University of Florida, Gainesville, Florida, USA

${ }^{11}$ Department of Neurology, University of Maryland, School of Medicine, Baltimore, MD, USA

${ }^{12}$ Department of Neurology, University of Cincinnati, Cincinnati, OH, USA

13 Department of Neurology, Henry Ford Hospital West Bloomfield, MI, USA

${ }^{14}$ AP-HP, Hopital de la Pitie-Salpetriere, Departement de Neurologie, Paris, France

${ }^{15}$ Sorbonne Universités, Institut du Cerveau_Paris Brain Institute-ICM, INSERM 1127, CNRS 7225, Paris, France

${ }^{16}$ Department of Neurology and Human Genetics, Emory University, Atlanta, GA, USA
}

Running head: Quality of life in dystonia

Title character count: 70

Number of words in abstract: $215(<250)$

Number of words in main text: $2815(<3500)$

Number of references: 47 (> 40)

Number of figures: 1

Number of tables: 2

Supplementay files: 1

\section{Corresponding Author:}

Norbert Brüggemann, MD

Dept. of Neurology and Institute of Neurogenetics, University of Lübeck

Ratzeburger Allee 160

Lübeck, SH, 23538, Germany

Phone +49-451-500 43401

Fax +49-451-500 43404

norbert.brueggemann@neuro.uni-luebeck.de 


\begin{tabular}{|c|c|}
\hline Johanna Junker & johanna.junker@neuro.uni-luebeck.de \\
\hline Brian D. Berman & brian.berman@cuanschutz.edu \\
\hline James Hall & J.E.Hall@soton.ac.uk \\
\hline Deena Wahba & dwwahba@gmail.com \\
\hline Valerie Brandt & V.C.Brandt@soton.ac.uk \\
\hline Joel S. Perlmutter & perlmutterjoel@wustl.edu \\
\hline Joseph Jankovic & josephj@bcm.edu \\
\hline Irene A. Malaty & irene.malaty@neurology.ufl.edu \\
\hline Aparna Wagle Shukla & aparna.shukla@neurology.ufl.edu \\
\hline Stephen G. Reich & SReich@som.umaryland.edu \\
\hline Alberto J. Espay & alberto.espay@uc.edu \\
\hline Kevin R. Duque & duqueykr@ucmail.uc.edu \\
\hline Neepa Patel & npatel20@hfhs.org \\
\hline Emmanuel Roze & emmanuel.flamand-roze@aphp.fr \\
\hline Marie Vidailhet & marie.vidailhet@aphp.fr \\
\hline H. A. Jinnah & hjinnah@emory.edu \\
\hline
\end{tabular}

Co-investigators: see supplementary file

Keywords: Dystonia, Quality of life, Depression, Anxiety 


\section{ABSTRACT}

Objective: To evaluate the relationship between health-related quality of life (HR-QoL) and both physical and psychiatric factors in a large, international, multicenter cohort of isolated dystonia patients, the Dystonia Coalition.

Methods: Natural history data from 603 patients with isolated dystonia (median age 57 years (IQR: 48-64 years), 67.0\% female) were prospectively acquired and analyzed. HR-QoL (RAND 36-Item Health Survey), severity of depressive symptoms, generalized anxiety (Hospital Anxiety and Depression Scale) and social anxiety (Liebowitz Social Anxiety Scale) were assessed. Dystonia severity (Burke-Fahn-Marsden Dystonia Rating Scale) and dystonic tremor were examined. Statistical predictors of HR-QoL were calculated using saturated path analysis.

Results: Reduced HR-QoL was strongly associated with the degree of depressive symptoms and generalized and social anxiety (8/8 RAND36 subscales, $p \leq .001)$. Increased dystonia severity was associated with worse physical functioning, physical and emotional role functioning, and social functioning (all $p \leq .001$ ). The presence of tremor correlated with worse physical functioning and pain (all $p \leq .006$ ). Younger age was associated with reduced emotional well-being and vitality (all $\mathrm{p} \leq .006$ ). There were no HR-QoL differences between sexes.

Conclusion: HR-QoL in isolated dystonia is strongly associated with psychiatric and physical features. While current standard of care focus on motor aspects of dystonia, comprehensive care should address both physical and mental aspects of health. 


\section{INTRODUCTION}

Health-related quality of life (HR-QoL) is reduced in patients with dystonia compared to population-based samples. ${ }^{1-4} \mathrm{HR}-\mathrm{Q}$ oL in dystonia is not only determined by motor symptoms (MS) including dystonia severity and dystonic tremor but also by non-motor symptoms (NMS), i.e. depression, anxiety, social phobia, low self-esteem and pain. ${ }^{35} \mathrm{NMS}$ are frequent in dystonia in comparison to population-based samples, which have an annual prevalence of 7\% for depression, ${ }^{6}$ 1-6\% for generalized anxiety disorder (GAD) $)^{7-9}$ and $2-8 \%$ for social anxiety disorder (SAD)..$^{910}$ The point prevalence in dystonia is $16-48 \%$ for depression, $20-50 \%$ for GAD and $40 \%$ for SAD. ${ }^{5} 11-14$ The relationship between MS and NMS is poorly understood, i.e. to which extent NMS are secondary due to MS or a result of impaired neuronal processing. ${ }^{15}$

Previous studies in dystonia aimed to reveal the relationship of HR-QoL with MS and NMS. ${ }^{15-}$

17 Their significance, however, has been limited due to relatively small sample sizes and methodological differences for example between self-evaluation of dystonia severity vs. rating of dystonia by an experienced investigator. ${ }^{15-17}$ Thus, no systematic analysis of the influence of MS and NMS severity on HR-QoL has yet been performed in a comprehensive dystonia cohort. Here, we analyzed data from the Dystonia Coalition cohort, a large prospectively investigated and international sample of isolated dystonia patients, and hypothesized that psychiatric manifestations have a higher impact on HR-QoL than dystonia severity and tremor. Mental health of dystonia patients and its overall burden on HR-QoL may not be well addressed since dystonia treatment mainly focuses on the motor aspects of the disease. 


\section{METHODS}

\section{Participants}

The analysis included participants' data from baseline assessment of the Natural History Project of the Dystonia Coalition clinical database enrolled between 12 January 2011 and 3 November 2017 across 36 clinical sites (USA, Canada, Australia, Germany, France, Italy). Additional Dystonia Coalition investigators that contributed subjects to the study are listed in Supplementary File. The Dystonia Coalition is a multicenter study of isolated dystonia patients, aged 18 years and older, and the Natural History Project includes patients with dystonia onset no more than five years prior to study enrollment (https://www.rarediseasesnetwork.org/cms/dystonia).

Participants answered a standardized questionnaire and were clinically examined using a standardized protocol. Dystonia patients with botulinum toxin (BoNT) treatment were enrolled when symptoms returned. This usually meant they were enrolled 3 months after treatment, but never less than two months after treatment. Exclusion criteria were secondary and combined dystonia and medical/neurological conditions confounding diagnoses or precluding a complete assessment. For the current study a small group of patients with a confirmed mutation in a dystonia-related gene were excluded $(n=12)$ as certain monogenic forms, e.g. SGCE-related dystonia, exhibit a specific neuropsychiatric profile and are thus accompanied by a high burden of NMS. ${ }^{18}$

Classification of dystonia referring to body distribution was conducted according to Albanese et al.. ${ }^{19}$ Type of dystonia was divided into focal, segmental, multifocal and generalized dystonia. Focal dystonia was further divided into blepharospasm, oromandibular/lingual, laryngeal, cervical and limb dystonia. 


\section{Standard Protocol Approvals and Patient Consents}

All participants gave written informed consent for study participation prior to study enrollment. The study was approved by the local ethics committees of all clinical sites.

\section{Questionnaire and Rating Scales}

HR-QoL and NMS were evaluated by generic, validated and widely used rating scales (RAND 36-Item Health Survey, Hospital Anxiety and Depression Scale, Liebowitz Social Anxiety Scale) to allow for comparison with other dystonia and movement disorder studies. ${ }^{20-22}$

\section{Dystonia Coalition Questionnaire}

Demographic and clinical data included sex, age, affected body regions, the presence of other movement disorders including tremor, age at onset, disease duration, medical treatment for dystonia, medical history and mutations in dystonia-related genes.

\section{RAND 36-Item Health Survey}

HR-QoL was evaluated using the RAND 36-Item Health Survey 1.0. The RAND 36 is a generic quality of life questionnaire to measure physical and mental well-being, relies upon patient self-reporting, and was developed in the Medical Outcome Study. ${ }^{20}$ It contains 36 questions representing the following eight subscales: general health, physical functioning, role limitations due to physical health problems, pain, energy/fatigue, emotional well-being, role limitations due to emotional problems and social functioning. The questions are rated on a Likert Scale with up to six response options and seven questions are answered with yes or no. Original response categories are recoded to values of a 0 to $100 \%$ range and the items of each of the 8 subscales are averaged. A high score represents a better health state. The 
RAND 36-Item Health Survey 1.0 and the 36-Item Short Form Survey (SF-36) include the same items, while the scoring algorithm is different regarding the general health and pain scales. $^{23}$ The scoring algorithm of the RAND 36-Item Health Survey 1.0 was used in this study.

Hospital Anxiety and Depression Scale (HADS)

Severity of generalized anxiety and depressive symptoms was assessed by the self-reported Hospital Anxiety and Depression Scale version $4 .{ }^{21}$ Each of the two subscales (HADS-A, HADSD) contain seven questions rated on a 4-point scale (0-3), each subscale yielding score ranging from 0 to 21 . Standard scale cut-offs indicated the presence of depression and anxiety (HADS-A > 7, HADS-D > 7).

Liebowitz Social Anxiety Scale (LSAS)

The self-reported LSAS is a 24-item scale divided into two subscales assessing fear/anxiety concerning performance and pertaining to social situations as well as avoidance behavior. ${ }^{22}$ The 24 items of the two subscales are rated on a Likert Scale from 0 to 3 yielding a maximum sum score of 144 . The presence of social anxiety was indicated by a standard scale cut-off $>$ 30.

\section{Examination protocol and rating}

Standardized examination of all patients included evaluation of eyes, mouth, tongue, neck, arms, hands, legs and feet and the examination of speech, voice, swallowing, handwriting, standing and walking. ${ }^{24} \mathrm{~A}$ movement disorder neurologist evaluated dystonia severity across different body regions using the validated Burke-Fahn-Marsden Dystonia Rating Scale 
(BFMDRS). ${ }^{25}$ Tremor was assessed by observing all body regions for the occurrence of tremor regardless of its amplitude, frequency or regularity. The BFMDRS evaluates provoking (scale 0-4) and severity factors (scale 0-4) of nine different body parts (eyes, mouth, speech/swallowing, neck, right arm, left arm, right leg, left leg, trunk). For each body part, provoking factor, severity factor and a weight factor (0.5 or 1 ) were multiplied yielding score ranges from 0 to 120 , with higher scores indicating more severe dystonia.

\section{Statistical analysis}

To analyze the relationship between MS and NMS with HR-QoL, simultaneously estimated bivariate correlations were obtained from a saturated path analysis performed in MPlus version 7.4. ${ }^{26}$ The eight subscales of the RAND 36-Item Health Survey, the three NMS scores (HADS-D, HADS-A, LSAS), and the two MS factors (BFMDRS, tremor (yes/no)) were entered into the model, as well as age and sex to control for their effects. The Full Information Maximum Likelihood (FIML) statistical procedure was used for replacement of missing values in the path analysis that was undertaken. Bonferroni-corrected alphas were calculated to adjust for multiple comparisons (simultaneous correlations), and P-values $\leq 0.006$ were considered significant.

Differences regarding the severity of NMS between patients with and without antidepressants were assessed using t-tests for independent samples. All tests of significance were two-sided. Bonferroni-corrected alphas $\leq 0.017$ were considered significant. 


\section{Data Availability}

Anonymized data (study protocol, statistical analysis) will be shared by request from any qualified investigator. Data will be available for 10 years.

\section{RESULTS}

Out of 615 participants, 12 were excluded due to secondary or combined dystonia or a confirmed mutation in a dystonia-related gene. Of the remaining 603 isolated dystonia patients, $1.5 \%$ of data points were missing.

The majority of patients were female $(67.0 \%, 404 / 603)$. The median age at baseline examination was 57 years (IQR: $48-64$ years), and the median age at dystonia onset 54 years (IQR: 45-61 years). Table 1 displays mean BFMDRS scores, the ratio of patients with tremor, mean total scores of RAND 36-Item Health Survey, HADS-D, HADS-A and LSAS as well as the ratio of patients with symptoms of a depression (HADS-D > 7), GAD (HADS-A > 7) and SAD (LSAS > 30). In detail, symptoms of depression were found in $22 \%$, symptoms of GAD in $37 \%$ and SAD in $44 \%$ of patients. 
Table 1. Clinical data of the study cohort

\begin{tabular}{|c|c|c|c|c|c|c|}
\hline & HR-QoL & Depression & $\begin{array}{c}\text { Generalized } \\
\text { Anxiety }\end{array}$ & $\begin{array}{c}\text { Social } \\
\text { Anxiety }\end{array}$ & BFMDRS & Tremor \\
\hline All $(n=603)$ & $63.6 \pm 21.8$ & $\begin{array}{c}21.5 \% \\
(127 / 591) \\
4.6 \pm 4.0\end{array}$ & $\begin{array}{c}36.7 \% \\
(217 / 591) \\
6.4 \pm 4.2\end{array}$ & $\begin{array}{c}44.3 \% \\
(262 / 591) \\
32.1 \pm 26.0\end{array}$ & $6.7 \pm 5.0$ & $\begin{array}{c}43 \% \\
(259 / 603)\end{array}$ \\
\hline $\begin{array}{l}\text { Main groups of } \\
\text { dystonia } \\
\quad \text { focal }(n=373)\end{array}$ & $66.3 \pm 21.8$ & $\begin{array}{c}20.0 \% \\
(73 / 365) \\
4.4 \pm 4.0\end{array}$ & $\begin{array}{c}37.3 \% \\
(136 / 365) \\
6.4 \pm 4.1\end{array}$ & $\begin{array}{c}41.5 \% \\
(152 / 366) \\
30.9 \pm 25.4\end{array}$ & $4.4 \pm 2.4$ & $\begin{array}{c}44.0 \% \\
(164 / 373)\end{array}$ \\
\hline segmental ( $n=171)$ & $58.0 \pm 21.0$ & $\begin{array}{c}24.6 \% \\
(41 / 167) \\
5.4 \pm 4.1\end{array}$ & $\begin{array}{c}36.5 \% \\
(61 / 167) \\
6.7 \pm 4.2\end{array}$ & $\begin{array}{c}55.1 \% \\
(92 / 167) \\
36.8 \pm 26.7\end{array}$ & $9.8 \pm 5.3$ & $\begin{array}{c}39.8 \% \\
(68 / 171)\end{array}$ \\
\hline multifocal ( $n=49$ ) & $64.4 \pm 20.9$ & $\begin{array}{c}20.4 \% \\
(10 / 49) \\
3.9 \pm 3.3\end{array}$ & $\begin{array}{c}30.6 \% \\
(15 / 49) \\
5.3 \pm 4.2\end{array}$ & $\begin{array}{c}30.6 \% \\
(15 / 49) \\
25.9 \pm 24.7\end{array}$ & $9.5 \pm 4.4$ & $\begin{array}{c}42.9 \% \\
(21 / 49)\end{array}$ \\
\hline generalized $(n=10)$ & $58.1 \pm 24.9$ & $\begin{array}{c}30 \% \\
(3 / 10) \\
5.0 \pm 4.4\end{array}$ & $\begin{array}{c}50 \% \\
(5 / 10) \\
7.3 \pm 5.3\end{array}$ & $\begin{array}{c}33.3 \% \\
(3 / 9) \\
29.4 \pm 34.3\end{array}$ & $21.4 \pm 9.4$ & $\begin{array}{c}60 \% \\
(6 / 10)\end{array}$ \\
\hline $\begin{array}{l}\text { Subgroups of focal } \\
\text { dystonia } \\
\text { blepharospasm } \\
(n=41)\end{array}$ & $70.8 \pm 20.3$ & $\begin{array}{c}19.5 \% \\
(8 / 41) \\
4.3 \pm 4.2\end{array}$ & $\begin{array}{c}24.4 \% \\
(10 / 41) \\
5.3 \pm 4.1\end{array}$ & $\begin{array}{c}19.5 \% \\
(8 / 41) \\
24.2 \pm 25.8\end{array}$ & $4.6 \pm 2.3$ & $\begin{array}{l}14.6 \% \\
(6 / 41)\end{array}$ \\
\hline $\begin{array}{l}\text { oromandibular } \\
\text { /lingual } \\
(n=22)\end{array}$ & $67.7 \pm 19.9$ & $\begin{array}{c}18.2 \% \\
(4 / 22) \\
4.7 \pm 4.0\end{array}$ & $\begin{array}{c}22.7 \% \\
(5 / 22) \\
5.5 \pm 3.5\end{array}$ & $\begin{array}{c}36.4 \% \\
(8 / 22) \\
27.9 \pm 20.0\end{array}$ & $3.8 \pm 3.0$ & $\begin{array}{l}27.3 \% \\
(6 / 22)\end{array}$ \\
\hline $\begin{array}{l}\text { laryngeal } \\
(n=30)\end{array}$ & $77.1 \pm 15.6$ & $\begin{array}{c}13.3 \% \\
(4 / 30) \\
3.1 \pm 3.1\end{array}$ & $\begin{array}{c}46.7 \% \\
(14 / 30) \\
7.8 \pm 4.3\end{array}$ & $\begin{array}{c}66.7 \% \\
(20 / 30) \\
40.7 \pm 23.6\end{array}$ & $3.1 \pm 1.8$ & $\begin{array}{c}33.3 \% \\
(10 / 30)\end{array}$ \\
\hline $\begin{array}{l}\text { cervical } \\
(n=227)\end{array}$ & $62.3 \pm 22.6$ & $\begin{array}{c}23.2 \% \\
(51 / 220) \\
4.7 \pm 4.1\end{array}$ & $\begin{array}{c}41.8 \% \\
(92 / 220) \\
6.8 \pm 4.2\end{array}$ & $\begin{array}{c}45.0 \% \\
(99 / 220) \\
33.1 \pm 26.8\end{array}$ & $4.7 \pm 2.3$ & $\begin{array}{c}57.3 \% \\
(130 / 227)\end{array}$ \\
\hline $\begin{array}{l}\operatorname{limb} \\
(n=53)\end{array}$ & $73.1 \pm 18.9$ & $\begin{array}{c}11.5 \% \\
(6 / 52) \\
3.4 \pm 3.3\end{array}$ & $\begin{array}{c}28.8 \% \\
(15 / 52) \\
5.4 \pm 3.3\end{array}$ & $\begin{array}{c}32.1 \% \\
(17 / 53) \\
22.8 \pm 17.8\end{array}$ & $3.8 \pm 2.5$ & $\begin{array}{c}22.6 \% \\
(12 / 53)\end{array}$ \\
\hline
\end{tabular}


With regard to therapy, 68.0\% (410/603) were treated with BoNT, 39.5\% (238/603) with oral anti-dystonic drugs (anticholinergics, benzodiazepines, non-benzo hypnotics, dopaminergics, antidopaminergics, muscle relaxants) and $19.1 \%$ with antidepressants. The group of patients with antidepressants (depression: $6.3 \pm 4.3$ vs. $4.2 \pm 3.8(M \pm S D), t(589)=-5.1, p<0.000$; GAD: $8.2 \pm 4.2$ vs. $6.0 \pm 4.0(M \pm S D), t(589)=-5.3, p<0.000 ; S A D: 38.6 \pm 30.0$ vs. $30.6 \pm 24.7$ $(M \pm S D), t(589)=-3.0, p=0.003)$ exhibited higher depression and anxiety scores. None of the patients had deep brain stimulation, whereas $0.8 \%$ of patients had previously received other surgical treatment for dystonia (myectomy for blepharospasm or spasmodic dysphonia $(n=3)$, selective denervation for cervical dystonia $(n=2))$.

\section{Influence of MS and NMS on HR-QoL in dystonia}

The results of the path analysis with numerical estimates as indicators of the strength of the relationships between the eight HR-QoL subscales (RAND 36-Item Health Survey) and dystonia severity (BFMDRS), tremor, severity of depressive symptoms (HADS-D), GAD (HADSA) and SAD (LSAS), as well as age at examination and sex are displayed in Table 2 and Figure 1. Lower HR-QoL of all eight subscales related to more severe depressive symptoms, GAD and SAD (all $p \leq .001)$. Depressive symptoms presented with highest (-0.47 up to -0.72 ) and social anxiety with lowest estimates $(-0.23$ up to -0.42$)$. Higher dystonia severity was associated with lower physical functioning, physical and emotional role functioning, and social functioning (all $p \leq .001$ ), and the presence of tremor was associated with lower HRQoL regarding physical functioning and pain (all $p \leq .006$ ). Both dystonia severity and tremor presented low estimates $(-0.09$ up to -0.24$)$. Younger age was associated with reduced emotional well-being and vitality (all $p \leq .006$, estimates 0.13 to 0.15 ). Sex was not associated with any differences in HR-QoL subscales. 
Table 2. Simultaneously estimated bivariate correlations obtained from a saturated path analysis

\begin{tabular}{|c|c|c|c|c|c|c|c|}
\hline $\begin{array}{l}\text { Health-Related } \\
\text { Quality of Life } \\
\text { subscale }\end{array}$ & $\begin{array}{l}\text { Dystonia } \\
\text { Severity }\end{array}$ & Tremor & Depression & $\begin{array}{l}\text { Generalized } \\
\text { Anxiety }\end{array}$ & $\begin{array}{l}\text { Social } \\
\text { Anxiety }\end{array}$ & Age & Sex \\
\hline $\begin{array}{l}\text { General } \\
\text { Health }\end{array}$ & $\begin{array}{l}-0.09 \\
(-0.17 \text { to } \\
-0.01)\end{array}$ & $\begin{array}{l}-0.05 \\
(-0.13 \text { to } \\
0.03)\end{array}$ & $\begin{array}{l}-0.50 * * * \\
(-0.57 \text { to } \\
-0.44)\end{array}$ & $\begin{array}{l}-0.40 * * * \\
(-0.47 \text { to } \\
-0.33)\end{array}$ & $\begin{array}{l}-0.31 * * * \\
(-0.39 \text { to } \\
-0.22)\end{array}$ & $\begin{array}{l}0.07 \\
(-0.01 \text { to } \\
0.15)\end{array}$ & $\begin{array}{l}-0.04 \\
(-0.12 \text { to } \\
0.04)\end{array}$ \\
\hline $\begin{array}{l}\text { Physical } \\
\text { Functioning }\end{array}$ & $\begin{array}{l}-0.14 * * * \\
(-0.22 \text { to } \\
-0.06)\end{array}$ & $\begin{array}{l}-0.14 * * * \\
(-0.22 \text { to } \\
-0.06)\end{array}$ & $\begin{array}{l}-0.47^{* * *} \\
(-0.54 \text { to } \\
-0.4)\end{array}$ & $\begin{array}{l}-0.27^{* * *} \\
(-0.35 \text { to } \\
-0.18)\end{array}$ & $\begin{array}{l}-0.27^{* * *} \\
(-0.36 \text { to } \\
-0.18)\end{array}$ & $\begin{array}{l}-0.07 \\
(-0.15 \text { to } \\
0.01)\end{array}$ & $\begin{array}{l}-0.07 \\
(-0.15 \text { to } \\
0.002)\end{array}$ \\
\hline $\begin{array}{l}\text { Physical Role } \\
\text { Functioning }\end{array}$ & $\begin{array}{l}-0.24 * * * \\
(-0.32 \text { to } \\
-0.16)\end{array}$ & $\begin{array}{l}-0.01 \\
(-0.09 \text { to } \\
0.07)\end{array}$ & $\begin{array}{l}-0.49 * * * \\
(-0.55 \text { to } \\
-0.43)\end{array}$ & $\begin{array}{l}-0.35^{* * *} \\
(-0.42 \text { to } \\
-0.28)\end{array}$ & $\begin{array}{l}-0.26 * * * \\
(-0.34 \text { to } \\
-0.2)\end{array}$ & $\begin{array}{l}0.08 \\
(0.003 \text { to } \\
0.16)\end{array}$ & $\begin{array}{l}-0.06 \\
(-0.14 \text { to } \\
0.02)\end{array}$ \\
\hline Pain & $\begin{array}{l}-0.10 \\
(-0.19 \text { to } \\
-0.001)\end{array}$ & $\begin{array}{l}-0.11 * * \\
(-0.19 \text { to } \\
-0.03)\end{array}$ & $\begin{array}{l}-0.52 * * * \\
(-0.58 \text { to } \\
-0.45)\end{array}$ & $\begin{array}{l}-0.38 * * * \\
(-0.46 \text { to } \\
-0.31)\end{array}$ & $\begin{array}{l}-0.23 * * * \\
(-0.32 \text { to } \\
-0.14)\end{array}$ & $\begin{array}{l}0.11 \\
(0.03 \text { to } 0.2)\end{array}$ & $\begin{array}{l}-0.07 \\
(-0.15 \text { to } \\
0.01)\end{array}$ \\
\hline $\begin{array}{l}\text { Energy/ } \\
\text { Fatigue }\end{array}$ & $\begin{array}{l}-0.09 \\
(-0.17 \text { to } \\
-0.01)\end{array}$ & $\begin{array}{l}-0.09 \\
(-0.18 \text { to } \\
-0.01)\end{array}$ & $\begin{array}{l}-0.66 * * * \\
(-0.71 \text { to } \\
-0.61)\end{array}$ & $\begin{array}{l}-0.45 * * * \\
(-0.51 \text { to } \\
-0.38)\end{array}$ & $\begin{array}{l}-0.34 * * * \\
(-0.41 \text { to } \\
-0.27)\end{array}$ & $\begin{array}{l}0.13 * * \\
(0.05 \text { to } \\
0.21)\end{array}$ & $\begin{array}{l}-0.05 \\
(-0.13 \text { to } \\
0.03)\end{array}$ \\
\hline $\begin{array}{l}\text { Emotional } \\
\text { Well-being }\end{array}$ & $\begin{array}{l}-0.11 \\
(-0.2 \text { to } \\
-0.02)\end{array}$ & $\begin{array}{l}-0.002 \\
(-0.08 \text { to } \\
0.08)\end{array}$ & $\begin{array}{l}-0.72 * * * \\
(-0.76 \text { to } \\
-0.67)\end{array}$ & $\begin{array}{l}-0.68 * * * \\
(-0.72 \text { to } \\
-0.63)\end{array}$ & $\begin{array}{l}-0.41^{* * *} \\
(-0.49 \text { to } \\
-0.33)\end{array}$ & $\begin{array}{l}0.15 * * * \\
(0.07 \text { to } \\
0.22)\end{array}$ & $\begin{array}{l}0.01 \\
(-0.07 \text { to } \\
0.09)\end{array}$ \\
\hline $\begin{array}{l}\text { Emotional Role } \\
\text { Functioning }\end{array}$ & $\begin{array}{l}-0.17 * * * \\
(-0.26 \text { to } \\
-0.09)\end{array}$ & $\begin{array}{l}0.02 \\
(-0.06 \text { to } \\
0.1)\end{array}$ & $\begin{array}{l}-0.49 * * * \\
(-0.56 \text { to } \\
-0.42)\end{array}$ & $\begin{array}{l}-0.42 * * * \\
(-0.48 \text { to } \\
-0.35)\end{array}$ & $\begin{array}{l}-0.32 * * * \\
(-0.4 \text { to } \\
-0.24)\end{array}$ & $\begin{array}{l}0.11 \\
(0.03 \text { to } \\
0.19)\end{array}$ & $\begin{array}{l}0.01 \\
(-0.07 \text { to } \\
0.09)\end{array}$ \\
\hline $\begin{array}{l}\text { Social } \\
\text { Functioning }\end{array}$ & $\begin{array}{l}-0.23 * * * \\
(-0.32 \text { to } \\
-0.15)\end{array}$ & $\begin{array}{l}-0.004 \\
(-0.09 \text { to } \\
0.08)\end{array}$ & $\begin{array}{l}-0.67 * * * \\
(-0.72 \text { to } \\
-0.62)\end{array}$ & $\begin{array}{l}-0.44^{* * *} \\
(-0.5 \text { to } \\
-0.37)\end{array}$ & $\begin{array}{l}-0.42 * * * \\
(-0.5 \text { to } \\
-0.35)\end{array}$ & $\begin{array}{l}0.10 \\
(0.02 \text { to } \\
0.18)\end{array}$ & $\begin{array}{l}0.05 \\
(-0.03 \text { to } \\
0.14)\end{array}$ \\
\hline
\end{tabular}

\section{DISCUSSION}

Symptoms of depression, GAD and SAD are related to worse HR-QoL in dystonia patients in the large international Dystonia Coalition cohort. We found an additional association of HRQoL with dystonia severity, tremor and age at examination. Twenty percent of our patients were treated with antidepressants. The degree of underlying depressive symptoms and anxiety may thus have been underestimated.

Our results are in keeping with previous studies in smaller samples of patients with dystonia, which have already indicated that depression, GAD, low self-esteem, embarrassment and acceptance of illness are important determinants of HR-QoL. ${ }^{3} 16172728$ Motor severity was, however, not as strongly associated with HR-QoL in our study. The weaker association with 
motor severity may be due to the fact that we used the BFMDRS to assess dystonia severity which is a validated ${ }^{25}$ and commonly used rating scale but it may not be sensitive enough for focal dystonias. In keeping with this notion, most patients had focal or segmental dystonia in our sample whereas generalized (10/603) and multifocal (49/603) dystonias were less common. Other studies have also found a stronger relationship of QoL with NMS than with MS but this may again be attributable to the heterogeneity of dystonia subtypes in different cohorts and especially in those with smaller sample sizes and the use of different rating scales (BFMDRS, TWSTRS, Tsui score, UDRS). ${ }^{31127}$ Furthermore, the examination of patients under BoNT treatment at different time intervals limits the comparability of results. Of note, almost $70 \%$ of our patients were treated with BoNT about three months prior to the examination, indicating that dystonia severity may have been potentially higher in some patients without long-term BoNT therapy ${ }^{29}$ and may have resulted in stronger associations with lower HR-QoL. Thus, it is conceivable that the impact of MS severity in our and previous studies may be lessened by the availability and ongoing utilization of effective treatments as BoNT and DBS with positive long-term effects on HR-QoL, ${ }^{30}$ as compared to the potentially less uniform implementation of treatments for the NMS. MS and MS-related pain should of course be treated to improve and stabilize HR-QoL. ${ }^{31-35}$

Dystonic tremor is a frequent clinical sign in dystonia ${ }^{36}$ and tremor is a source of reduced QoL in other tremor types. ${ }^{37}$ The impact of dystonic tremor on HR-QoL in dystonia patients has previously not been sufficiently addressed. We found that dystonic tremor was negatively associated with physical functioning and pain-related QoL. Although patients were evaluated as symptoms returned after BoNT treatment, a sustained improvement in patients with long-term BoNT therapy cannot be excluded. Therefore, investigations of 
BoNT-naive patients may reveal even stronger associations. Our results implicate the importance of treating dystonic tremor to improve HR-QoL.

Population-based studies illustrate age- and sex-dependent prevalence of psychiatric conditions with a decrease in people $>50$ years of age and women being more anxious..$^{6-8}$ Controlling our analysis for age and sex, HR-QoL in dystonia patients did not differ between men and women, while younger age in dystonia was associated with reduced emotional well-being and vitality.

The question of whether NMS are a primary phenomenon of the disease or a secondary response to physical impairment remains unanswered. ${ }^{15}$ In dystonia as well as in Parkinson`s disease the most potent predictors of HR-QoL appear to be depression and anxiety. ${ }^{38}{ }^{39} \mathrm{An}$ increased risk of recurrent major depressive episodes in manifesting and non-manifesting TOR1A mutation carriers argues for a primary phenomenon, ${ }^{40}$ while higher depression and anxiety scores in symptomatic but not in asymptomatic SCGE carriers may argue for this to be a secondary epiphenomenon with the limitation that in most SGCE carriers the mutated allele will be silenced. ${ }^{41}$ Recent reports of familial coaggregation of psychiatric comorbidities in dystonia and an impaired theory of mind in cervical dystonia support shared genetic factors. ${ }^{4243}$ High prevalences of social anxiety in dystonia and QoL predictors as low selfesteem, self-deprecation, and educational level in cervical dystonia ${ }^{16}$ point towards an impact of MS on HR-QoL although for most dystonias there may be a bidirectional and dynamic relationship between MS and NMS. ${ }^{15}$

Our study has certain limitations: The size of the cohort allows for drawing meaningful conclusions, even while controlling for important confounders, such as sex and age. Nevertheless further factors such as educational level, marital and socioeconomic status may significantly influence HR-QoL and were not assessed to guarantee statistical power. 
A considerable proportion of patients were treated with oral anti-dystonic drugs and/or antidepressants. Their influence on NMS was not controlled for because the mechanism of action strongly varies across drug classes and some patients received medication from more than one drug class and with different dosages. Given the different drug targets and the contradictory or independent mechanisms (e.g. dopaminergics vs. anti-dopaminergics or anti-dystonic vs. anti-depressive effects) as well as the co-medication in several patients we refrained from a combined analysis. One of the inclusion criteria was disease duration less than five years, which prevented the assessment of later disease stages. Another limitation of our study is that only carriers of known mutations in dystonia-related genes were excluded but that no systematic screening was performed. Furthermore, new genes may not have yet been identified at the time point of the study, e.g. VPS16 which was very recently described in the context of dominantly inherited isolated dystonia. ${ }^{44}$ The rationale to exclude patients with a monogenic background was to account for a potential confounder as they may present with a distinct neuropsychiatric profile and a different burden of NMS. The mutation frequency is, however, very low in isolated dystonia cases whereas the likelihood to identify causative mutations is considerably higher in combined or complex dystonias as previously shown in a large dystonia sample where exome sequencing was performed..$^{456}$ Further, mutations in dystonia-related genes are enriched in generalized or multifocal dystonia although it can be very rarely found in patients with focal dystonias. As most patients in our sample suffered from focal dystonia (62\%) we thus assume that the number of unidentified mutations will be relatively low. The BFMDRS is a validated ${ }^{25}$ and commonly used rating scale for dystonia but it may not be sensitive enough for focal dystonias. Furthermore, dystonic tremor is an important clinical feature that is not well reflected in currently used clinical scales. Accordingly, the qualitative assessment in this study (tremor 
yes/no) is no longer appropriate to account for the specific features of dystonic tremor including distribution in different body regions, frequency, amplitude, regularity in frequency and amplitude, and alleviating or provoking maneuvers. Another pre-requisite is the sensitivity of a clinical rating scale to change, e.g. due to treatment. This is reflected by a recent paper showing that the diagnosis of dystonic tremor is still problematic because of different opinions on its very definition even across experts. ${ }^{47}$

HR-QoL in isolated dystonia is strongly associated especially with NMS as well as less related to MS, while standard therapy regimens only concentrate on the physical symptoms. Comprehensive care of dystonia patients should address both physical and mental health and aim to improve acceptance of the disease and coping strategies. 


\section{TABLES}

\section{Table 1}

HR-QoL and BFMDRS: Mean RAND 36-Item Health Survey total scores (range 0-100\%) and mean BFMDRS scores with standard deviation of all patients and per type of dystonia.

Depression, GAD, SAD: Percentage and numbers of patients with symptoms of depression (HADS-D > 7), GAD (HADS-A > 7), SAD (LSAS > 30) and mean HADS-D, mean HADS-A and mean LSAS scores with standard deviation of all patients and per type of dystonia.

Tremor: Percentage and numbers of patients with dystonic tremor of all patients and per type of dystonia.

\section{Table 2}

Path analysis: Numerical estimates and $95 \%$ confidence intervals as indicators of the strength of the relationships between the eight HR-QoL subscales (RAND 36-Item Health Survey) and dystonia severity (BFMDRS), tremor, severity of depression (HADS-D), severity of generalized anxiety (HADSA), severity of social anxiety (LSAS), age and sex in 603 dystonia patients. ${ }^{* *}$ Bonferroni corrected alpha $\leq 0.006 ;{ }^{* *} p \leq .001$

\section{FIGURES}

Figure 1. Simultaneously estimated bivariate correlations obtained from a saturated path analysis

Stylized illustration to demonstrate the strength of the relationships between the eight HR-QoL subscales (RAND 36-Item Health Survey) and dystonia severity (BFMDRS), tremor, severity of depression (HADS-D), severity of generalized anxiety (HADS-A), severity of social anxiety (LSAS) in 603 dystonia patients. 


\section{AUTHOR CONTRIBUTIONS:}

Johanna Junker, acquisition of data, study concept and design, analysis and interpretation of data, drafting of manuscript

Brian D. Berman, acquisition of data, critical revision of manuscript for intellectual content James Hall, statistical analysis, critical revision of manuscript for intellectual content Deena Wahba, acquisition of data, critical revision of manuscript for intellectual content Valerie Brandt, statistical analysis, critical revision of manuscript for intellectual content Joel S. Perlmutter, acquisition of data, critical revision of manuscript for intellectual content Joseph Jankovic, acquisition of data, critical revision of manuscript for intellectual content Irene A Malaty, acquisition of data, critical revision of manuscript for intellectual content Aparna W. Shukla, acquisition of data, critical revision of manuscript for intellectual content Stephen G. Reich, acquisition of data, critical revision of manuscript for intellectual content Alberto J. Espay, acquisition of data, critical revision of manuscript for intellectual content Kevin R. Duque, acquisition of data, critical revision of manuscript for intellectual content Neepa Patel, acquisition of data, critical revision of manuscript for intellectual content Emmanuel Roze, acquisition of data, critical revision of manuscript for intellectual content Marie Vidailhet, acquisition of data, critical revision of manuscript for intellectual content H. A. Jinnah, acquisition of data, critical revision of manuscript for intellectual content Norbert Brüggemann, study concept and design, analysis and interpretation of data, study supervision, critical revision of manuscript for intellectual content

Statistical Analysis conducted by James Hall, DPhil, and Valerie Brandt, PhD, University of Southampton

\section{Acknowledgement}

We would like to thank Praveetha Patalay for her support.

\section{Author Disclosures:}

Johanna Junker has nothing to disclose.

Brian D. Berman has received research grant support from the Dystonia Coalition (receives the majority of its support through NIH grant NS065701 from the Office of Rare Diseases Research in the National Center for Advancing Translational Science and National Institute of Neurological Disorders and Stroke), Benign Essential Blepharospasm Research Foundation, Colorado Clinical \& Translational Science Institute and Center for Neuroscience, Tools4Patient, Parkinson's Foundation, and from Mary Rossick Kern and Jerome H. Kern. He is on the medical advisory board of the Benign Essential Blepharospasm Research Foundation and the National Spasmodic Torticollis Association.

James Hall has no financial or non-financial disclosures to declare.

Deena Wahba has nothing to disclose.

Valerie Brandt has received no financial or non-financial support relating to this project or the preparation of this paper. VB is currently receiving funding from the ROLI music company and Tourettes Action UK (TAPG2019) and the Academy of Medical Sciences Springboard Award.

Joel S. Perlmutter has received research funding from National Institutes of Health (NCATS, 
NINDS, NIA), Michael J Fox Foundation, Barnes-Jewish Hospital Foundation (Elliot Stein Family Fund and Parkinson disease research fund), American Parkinson Disease Association (APDA) Advanced Research Center at Washington University, Greater St. Louis Chapter of the APDA, Paula and Rodger Riney Fund, Jo Oertli Fund, the Murphy Fund, Huntington Disease Society of America, and CHDI. He has received honoraria from CHDI, Huntington Disease Study Group, Parkinson Study Group, Beth Israel Hospital (Harvard group), U Pennsylvania, Stanford U. He also is co-director for the Dystonia Coalition, which has received the majority of its support through the NIH (grants NS116025, NS065701 from the National Institutes of Neurological Disorders and Stroke TR 001456 from the Office of Rare Diseases Research at the National Center for Advancing Translational Sciences). Dr. Perlmutter serves as Director of Medical and Scientific Advisory Committee of the Dystonia Medical Research Foundation, Chair of the Scientific Advisory Committee of the Parkinson Study Group, Chair of the Standards Committee of the Huntington Study Group, member of the Scientific Advisory Board of the APDA, Chair of the Scientific and Publication Committee for ENROLL-HD, and member of the Education Committee of the Huntington Study Group.

Joseph Jankovic has received research/training funding from: AbbVie Inc; Acadia

Pharmaceuticals; Allergan, Inc; Biotek; Cerevel Therapeutics; CHDI Foundation; Dystonia Coalition; Emalex Biosciences, Inc; F. Hoffmann-La Roche Ltd; Huntington Study Group; Medtronic Neuromodulation; Merz Pharmaceuticals; Michael J Fox Foundation for Parkinson Research; National Institutes of Health; Neuraly, Inc.; Neurocrine Biosciences; Parkinson's Foundation; Parkinson Study Group; Prilenia Therapeutics; Revance Therapeutics, Inc; Teva Pharmaceutical Industries Ltd.

Irene A. Malaty has participated in research funded by the Parkinson Foundation (PF),

Tourette Association of America (TAA), Dystonia Coalition, AbbVie, Biogen, Boston Scientific, Eli Lilly, Impax, Neuroderm, Prilenia, Revance, Teva but has no owner interest in any pharmaceutical company. She is on the medical advisory board of the TAA. She has received travel compensation or honoraria from the TAA, PF, International Association of Parkinsonism and Related Disorders, Medscape, and Cleveland Clinic, and royalties from Robert rose publishers.

Aparna Wagle Shukla reports grants from the NIH and has received grant support from

Benign Essential Blepharospasm Research foundation, Dystonia Coalition, Dystonia Medical Research foundation, National Organization for Rare Disorders and grant support from NIH (KL2 and K23 NS092957-01A1). Reports receiving honoraria from Acadia, Cavion, Elsevier and MJFF in past; Participates as a co-I for several $\mathrm{NIH}$, foundation, and industry sponsored trials over the years but has not received honoraria.

Stephen G. Reich has active or recent grant support from NINDS and royalties from Springer and Informa. He has also seved as a consultant for Best Doctors and as a reviewer for UpToDate. He serves on the Data Safety Monitoring Board for Enterin.

Alberto J. Espay has received grant support from the NIH and the Michael J Fox Foundation; personal compensation as a consultant/scientific advisory board member for Abbvie, Neuroderm, Neurocrine, Amneal, Adamas, Acadia, Acorda, InTrance, Sunovion, Lundbeck, and USWorldMeds; publishing royalties from Lippincott Williams \& Wilkins, Cambridge University Press, and Springer; and honoraria from USWorldMeds, Acadia, and Sunovion

Kevin R. Duque reports no disclosures. 
Neepa Patel has received honoria as a speaker for USWorldMed and Teva and consultant for Revance and Acorda phramaceutical.

Emmanuel Roze served on scientific advisory boards for Orkyn, Aguettant, Merz-Pharma; received honoraria for speeches from Orkyn, Aguettant, Merz-Pharma, Everpharma, International Parkinson and Movement disorders Society; received research support from Merz-Pharma, Orkyn, Aguettant, Elivie, Ipsen, Everpharma, Fondation Desmarest, AMADYS, Fonds de Dotation Brou de Laurière, Agence Nationale de la Recherche; received travel grant from Vitalair, PEPS development, Aguettant, MerzPharma, Ipsen, Merck, Orkyn, Elivie, Adelia Medical, Dystonia Medical Research Foundation, International Parkinson and Movement disorders Society, European Academy of Neurology, International Association of Parkinsonism and Related Disorders

Marie Vidailhet has nothing to disclose.

H. A. Jinnah has active or recent grant support from the US government (National Institutes of Health), private philanthropic organizations (Cure Dystonia Now), academicallyoriented institutions (the Dystonia Study Group), and industry (Cavion Therapeutics, Ipsen Pharmaceuticals, Retrophin Inc.). Dr. Jinnah has also served on advisory boards or as a consultant for Allergan Inc., CoA Therapeutics, Cavion Therapeutics, and Retrophin Inc. He has received honoraria or stipends for lectures or administrative work from the American Academy of Neurology, the American Neurological Association, the Dystonia Medical Research Foundation, the International Neurotoxin Society, and the International Parkinson's Disease and Movement Disorders Society. Dr. Jinnah serves on the Scientific Advisory Boards for several private foundations including the Benign Essential Blepharospasm Research Foundation, Cure Dystonia Now, the Dystonia Medical Research Foundation, the Tourette Association of America, and Tyler's Hope for a Cure. He also is principle investigator for the Dystonia Coalition, which has received the majority of its support through the $\mathrm{NIH}$ (grants NS116025, NS065701 from the National Institutes of Neurological Disorders and Stroke TR 001456 from the Office of Rare Diseases Research at the National Center for Advancing Translational Sciences). The Dystonia Coalition has received additional material or administrative support from industry sponsors (Allergan Inc. and Merz Pharmaceuticals) as well as private foundations (The American Dystonia Society, Beat Dystonia, The Benign Essential Blepharospasm Foundation, Cure Dystonia Now, Dystonia Europe, Dystonia Inc., Dystonia Ireland, The Dystonia Medical Research Foundation, The Foundation for Dystonia Research, The National Spasmodic Dysphonia Association, and The National Spasmodic Torticollis Association).

Norbert Brüggemann received speaker's honoraria from Grünenthal, UCB, Abbvie and Teva. He served as consultant for Censa and Centogene. NB is funded by the DFG (BR4328.2-1, GRK1957), the Collaborative Center for X-linked Dystonia-Parkinsonism and the Else-Kröner Fresenius-Stiftung (HA17_2017).

\section{Study funding}

This work was supported in part by grants to the Dystonia Coalition, a consortium of the Rare Diseases Clinical Research Network (RDCRN) that is supported by the Office of Rare Diseases Research (ORDR) at the National Center for Advancing Clinical and Translational Studies (NCATS; U54 TR001456) in collaboration with the National Institute for Neurological Diseases and Stroke (NINDS; U54 NS065701 and U54 NS116025). 


\section{REFERENCES}

1. Muller J, Kemmler G, Wissel J, et al. The impact of blepharospasm and cervical dystonia on health-related quality of life and depression. J Neurol 2002;249(7):842-6. doi: 10.1007/s00415-002-0733-1

2. Lim VK. Health related quality of life in patients with dystonia and their caregivers in New Zealand and Australia. Mov Disord 2007;22(7):998-1003. doi: $10.1002 / \mathrm{mds} .21486$

3. Slawek J, Friedman A, Potulska A, et al. Factors affecting the health-related quality of life of patients with cervical dystonia and the impact of botulinum toxin type A injections. Funct Neurol 2007;22(2):95-100.

4. Page D, Butler A, Jahanshahi M. Quality of life in focal, segmental, and generalized dystonia. Mov Disord 2007;22(3):341-7. doi: 10.1002/mds.21234

5. Lewis L, Butler A, Jahanshahi M. Depression in focal, segmental and generalized dystonia. J Neurol 2008;255(11):1750-5. doi: 10.1007/s00415-008-0020-x

6. Center for Behavioral Health Statistics and Quality. Behavioral health trends in the United States: results from the 2014 National Survey on Drug Use and Health. HHS publication no SMA 15-4927, NSDUH series H-50 2015

7. Hinz A, Klein AM, Brahler E, et al. Psychometric evaluation of the Generalized Anxiety Disorder Screener GAD-7, based on a large German general population sample. J Affect Disord 2017;210:338-44. doi: 10.1016/j.jad.2016.12.012

8. Bandelow B, Michaelis S. Epidemiology of anxiety disorders in the 21st century. Dialogues in clinical neuroscience 2015;17(3):327-35.

9. Alonso J, Lepine JP, Committee ESMS. Overview of key data from the European Study of the Epidemiology of Mental Disorders (ESEMeD). J Clin Psychiatry 2007;68 Suppl 2:3-9.

10. Kessler RC, Petukhova M, Sampson NA, et al. Twelve-month and lifetime prevalence and lifetime morbid risk of anxiety and mood disorders in the United States. Int J Methods Psychiatr Res 2012;21(3):169-84. doi: 10.1002/mpr.1359

11. Gundel H, Wolf A, Xidara V, et al. Social phobia in spasmodic torticollis. J Neurol Neurosurg Psychiatry 2001;71(4):499-504.

12. Kuyper DJ, Parra V, Aerts S, et al. Nonmotor manifestations of dystonia: a systematic review. Mov Disord 2011;26(7):1206-17. doi: 10.1002/mds.23709

13. Moraru E, Schnider P, Wimmer A, et al. Relation between depression and anxiety in dystonic patients: implications for clinical management. Depress Anxiety 2002;16(3):100-3. doi: 10.1002/da.10039

14. Fabbrini G, Berardelli I, Moretti G, et al. Psychiatric disorders in adult-onset focal dystonia: a case-control study. Mov Disord 2010;25(4):459-65. doi: $10.1002 / \mathrm{mds} .22983$

15. Girach A, Vinagre Aragon A, Zis P. Quality of life in idiopathic dystonia: a systematic review. J Neurol 2018 doi: 10.1007/s00415-018-9119-x

16. Ben-Shlomo Y, Camfield L, Warner T, et al. What are the determinants of quality of life in people with cervical dystonia? J Neurol Neurosurg Psychiatry 2002;72(5):608-14.

17. Basurovic N, Svetel M, Pekmezovic T, et al. Evaluation of the quality of life in patients with segmental dystonia. Vojnosanitetski pregled Military-medical and pharmaceutical review 2012;69(9):759-64.

18. Kinugawa K, Vidailhet M, Clot F, et al. Myoclonus-dystonia: an update. Mov Disord 2009;24(4):479-89. doi: 10.1002/mds.22425 [published Online First: 2009/01/02] 
19. Albanese A, Bhatia K, Bressman SB, et al. Phenomenology and classification of dystonia: a consensus update. Mov Disord 2013;28(7):863-73. doi: $10.1002 / \mathrm{mds} .25475$

20. McHorney CA, Ware JE, Jr., Raczek AE. The MOS 36-Item Short-Form Health Survey (SF-36): II. Psychometric and clinical tests of validity in measuring physical and mental health constructs. Medical care 1993;31(3):247-63.

21. Bjelland I, Dahl AA, Haug TT, et al. The validity of the Hospital Anxiety and Depression Scale. An updated literature review. Journal of psychosomatic research 2002;52(2):69-77.

22. Rytwinski NK, Fresco DM, Heimberg RG, et al. Screening for social anxiety disorder with the self-report version of the Liebowitz Social Anxiety Scale. Depress Anxiety 2009;26(1):34-8. doi: 10.1002/da.20503

23. Hays RD, Sherbourne CD, Mazel RM. The RAND 36-Item Health Survey 1.0. Health economics 1993;2(3):217-27.

24. Yan L, Hicks M, Winslow K, et al. Secured web-based video repository for multicenter studies. Parkinsonism \& related disorders 2015;21(4):366-71. doi: 10.1016/j.parkreldis.2015.01.011

25. Burke RE, Fahn S, Marsden CD, et al. Validity and reliability of a rating scale for the primary torsion dystonias. Neurology 1985;35(1):73-7.

26. Muthén L, Muthéen B. Mplus user's guide. 7 ed. Los Angeles, 2012.

27. Soeder A, Kluger BM, Okun MS, et al. Mood and energy determinants of quality of life in dystonia. J Neurol 2009;256(6):996-1001. doi: 10.1007/s00415-009-5060-3

28. Pekmezovic T, Svetel M, Ivanovic N, et al. Quality of life in patients with focal dystonia. Clin Neurol Neurosurg 2009;111(2):161-4. doi: 10.1016/j.clineuro.2008.09.023

29. Quagliato EM, Carelli EF, Viana MA. A prospective, randomized, double-blind study comparing the efficacy and safety of type a botulinum toxins botox and prosigne in the treatment of cervical dystonia. Clin Neuropharmacol 2010;33(1):22-6. doi: 10.1097/WNF.0b013e3181c46f48

30. Tsuboi T, Cauraugh JH, Wong JK, et al. Quality of life outcomes after globus pallidus internus deep brain stimulation in idiopathic or inherited isolated dystonia: a meta-analysis. J Neurol Neurosurg Psychiatry 2020;91(9):938-44. doi: 10.1136/jnnp-2019-322575

31. Han V, Skorvanek M, Smit M, et al. Prevalence of non-motor symptoms and their association with quality of life in cervical dystonia. Acta Neurol Scand 2020 doi: 10.1111/ane.13304

32. Kawada T. Mental health and quality of life in patients with cervical dystonia. Neurol Sci 2020 doi: 10.1007/s10072-020-04428-z

33. $\mathrm{Pu} \mathrm{B}, \mathrm{Li} \mathrm{C}, \mathrm{Li} \mathrm{J}$, et al. Improvement of quality of life and mental health in patients with spasmodic torticollis after microvascular decompression. Clin Neurol Neurosurg 2019;180:57-60. doi: 10.1016/j.clineuro.2019.03.001

34. Molho ES, Stacy M, Gillard P, et al. Impact of Cervical Dystonia on Work Productivity: An Analysis From a Patient Registry. Movement disorders clinical practice 2016;3(2):130-38. doi: 10.1002/mdc3.12238

35. Balint B, Mencacci NE, Valente EM, et al. Dystonia. Nature reviews Disease primers 2018;4(1):25. doi: 10.1038/s41572-018-0023-6

36. Defazio G, Conte A, Gigante AF, et al. Is tremor in dystonia a phenotypic feature of dystonia? Neurology 2015;84(10):1053-9. doi: 10.1212/WNL.0000000000001341 
37. Louis ED, Machado DG. Tremor-related quality of life: A comparison of essential tremor vs. Parkinson's disease patients. Parkinsonism \& related disorders 2015;21(7):729-35. doi: 10.1016/j.parkreldis.2015.04.019

38. Slawek J, Derejko M, Lass P. Factors affecting the quality of life of patients with idiopathic Parkinson's disease--a cross-sectional study in an outpatient clinic attendees. Parkinsonism \& related disorders 2005;11(7):465-8. doi: 10.1016/j.parkreldis.2005.04.006

39. Carod-Artal FJ, Ziomkowski S, Mourao Mesquita H, et al. Anxiety and depression: main determinants of health-related quality of life in Brazilian patients with Parkinson's disease. Parkinsonism \& related disorders 2008;14(2):102-8. doi: 10.1016/j.parkreldis.2007.06.011

40. Heiman GA, Ottman R, Saunders-Pullman RJ, et al. Increased risk for recurrent major depression in DYT1 dystonia mutation carriers. Neurology 2004;63(4):631-7.

41. Foncke EM, Cath D, Zwinderman $\mathrm{K}$, et al. Is psychopathology part of the phenotypic spectrum of myoclonus-dystonia?: a study of a large Dutch M-D family. Cogn Behav Neurol 2009;22(2):127-33. doi: 10.1097/WNN.0b013e3181a7228f

42. Martino D, Brander G, Svenningsson P, et al. Association and Familial Coaggregation of Idiopathic Dystonia with Psychiatric Outcomes. Mov Disord 2020 doi: 10.1002/mds.28257 [published Online First: 2020/09/18]

43. Lagravinese G, Santangelo G, Bonassi G, et al. Affective and cognitive theory of mind in patients with cervical dystonia with and without tremor. Journal of neural transmission 2020 doi: 10.1007/s00702-020-02237-4 [published Online First: 2020/08/10]

44. Steel D, Zech M, Zhao C, et al. Loss-of-Function Variants in HOPS Complex Genes VPS16 and VPS41 Cause Early Onset Dystonia Associated with Lysosomal Abnormalities. Ann Neurol 2020;88(5):867-77. doi: 10.1002/ana.25879 [published Online First: 2020/08/19]

45. Zech M, Jech R, Boesch S, et al. Monogenic variants in dystonia: an exome-wide sequencing study. Lancet Neurol 2020;19(11):908-18. doi: 10.1016/s14744422(20)30312-4 [published Online First: 2020/10/26]

46. Lange LM, Klein C. Monogenic Causes of Dystonic Syndromes: Common in Dystonic Cerebral Palsy, Rare in Isolated Dystonia. Mov Disord 2020 doi: 10.1002/mds.28420 [published Online First: 2020/12/08]

47. Shaikh AG, Beylergil SB, Scorr L, et al. Dystonia \& tremor: A cross-sectional study of the dystonia coalition cohort. Neurology 2020 doi: 10.1212/wnl.0000000000011049 [published Online First: 2020/10/14] 